\title{
Association between intake of red and processed meat and the risk of heart failure: a meta-analysis
}

\author{
Kun Cui ${ }^{1}$, Yabin Liü ${ }^{2}$ Lingjun Zhu², Xia Mei ${ }^{1}$, Ping Jin ${ }^{1}$ and Yuhui Luo ${ }^{1 *}$
}

\begin{abstract}
Background: Many studies have assessed the association between consumption of red and processed meat and the risk of heart failure, but the results are not consistent. This meta-analysis aimed to comprehensively evaluate the relationship between intake of red and processed meat and the risk of heart failure.

Methods: Databases of Web of Knowledge, PubMed, and Wan Fang Med Online were retrieved up to date of August 31st, 2017. Suitable publications were identified through using the defined inclusion criteria. The summarized relative risk (RR) with the corresponding 95\% confidence interval (Cl) was calculated.

Results: Six scientific literatures were included in this study. In comparison with the lowest category, the summarized $\mathrm{RR}$ and $95 \% \mathrm{Cl}$ of the highest category of processed meat intake for heart failure risk was 1.23 (95\% Cl=1.07-1.41, $P^{2}=58.9 \%, P=0.045$ ). A significant connection between processed meat intake and heart failure was identified among the Europeans ( $R R=1.33,95 \% \mathrm{Cl}=1.15-1.54)$, but not the Americans. Yet few of essential association was found between heart failure risk and red meat intake ( $R R=1.04,95 \% \mathrm{Cl}=0.96-1.12$ ).
\end{abstract}

Conclusions: Findings of this meta-analysis indicated that the highest category of processed meat intake, other than red meat intake, correlated with an increased risk of heart failure.

Keywords: Dietary, Processed meat, Red meat, Heart failure, Meta-analysis

\section{Background}

Due to tremendous advance in modern medicine, the morbidity and mortality of heart failure reduces markedly. However, it remains a great burden to patients and their families [1]. It has been reported that 23 million people are suffering from the heart failure around the world $[1,2]$, which led to approximately $5 \%$ hospital admissions of all adults [3]. Epidemiologic studies indicated that genetic background is one of established risk factors for heart failure patients [4, 5]. Furthermore, other potential risk factors, such as dietary habits including fish consumption [6-8], vitamin D supplementation [9], antioxidant vitamin supplementation [10], fasting plasma glucose [11], and chocolate consumption [12, 13] are all investigated to show associations with heart

\footnotetext{
*Correspondence: luo_yuhui2017@yeah.net

'Department of Cardiology, Chongqing General Hospital, No.1, Youyi Road,

Yuzhong district, Chongqing 400016, People's Republic of China

Full list of author information is available at the end of the article
}

failure risk. Consumption of meat, including processed and red meat, has also been studied in relationship to risk of heart failure. Generally, processed meat contains high amounts of sodium, which may increase the risk of heart risk through its effect on blood pressure [14]. In addition, recent researches have shown that the intake of dietary meat no matter processed meat or red meat may be a risk factor for heart failure, but some inconsistency has been aroused between the consequences of the studies. The objective of this manuscript was to explore the association between intake of processed meat and red meat and risk of heart failure.

\section{Methods}

The current study was performed in accordance with the guidelines of Meta-analysis of Observational Studies and the Statement of Preferred Reporting Items for Systemic Meta-analysis [15]. 


\section{Literature search}

Studies were identified from the databases of Web of Knowledge, PubMed, and Wan Fang Med Online up to date of August 31st, 2017. The following research terms were used: 'heart failure' and 'red meat' (unprocessed) and/or 'processed meat'. Two investigators conducted this systematic research independently.

\section{Inclusion and exclusion criteria}

The inclusion criteria for studies in the present report were as following: (1) observational studies; (2) reporting the association between the intake of red meat and/or processed meat and the risk of heart failure; (3) the relative risk (RR) with the corresponding 95\% confidence interval (CI) were available; (4) human study; (5) articles published in English or Chinese languages.

\section{Data extraction and quality assessment}

The following relevant information were extracted: the first author's name, year of publication, region for conducting the study, study type, age, cases and participants, duration of follow-up, exposure classification, and confounders adjusted for and RR with 95\% CI for the association between the intake of processed meat and red meat and the heart failure risk. The Newcastle-Ottawa-Scale (NOS) was used for evaluating the quality of each study [16].

\section{Statistical analysis}

RR with 95\% CI was applied to combine the overall results [17]. Heterogeneity among the included studies was calculated with $\mathrm{I}^{2}$ statistical method [18]. The random effects model was employed [19]. Meta-regression analysis was performed to interpret the high betweenstudy heterogeneity [19]. Furthermore, sensitivity analysis was utilized to assess the stability of the results when a single study was removed. Potential publication bias was examined by using the Egger regression asymmetry test [20]. A two-sided $P<0.05$ indicated statistically significant difference. Statistical analysis was performed by utilizing the stata 12.0 software (STATA, College Station, TX, USA).

\section{Results}

\section{Search results}

Figure 1 displays the flow diagram of this study. The initial screening identified 399 articles from databases. After excluding duplications from the different databases, 321 articles were reviewed based on their titles and abstracts. Twenty-nine articles were further full text reviewed. The final analysis in this report included a total of 6 articles [21-26]. All of the studies had a prospective cohort design. Five studies were conducted to assess the association between the intake of processed meat and the risk of heart failure, while 5 studies evaluated the relationship between the red meat intake and

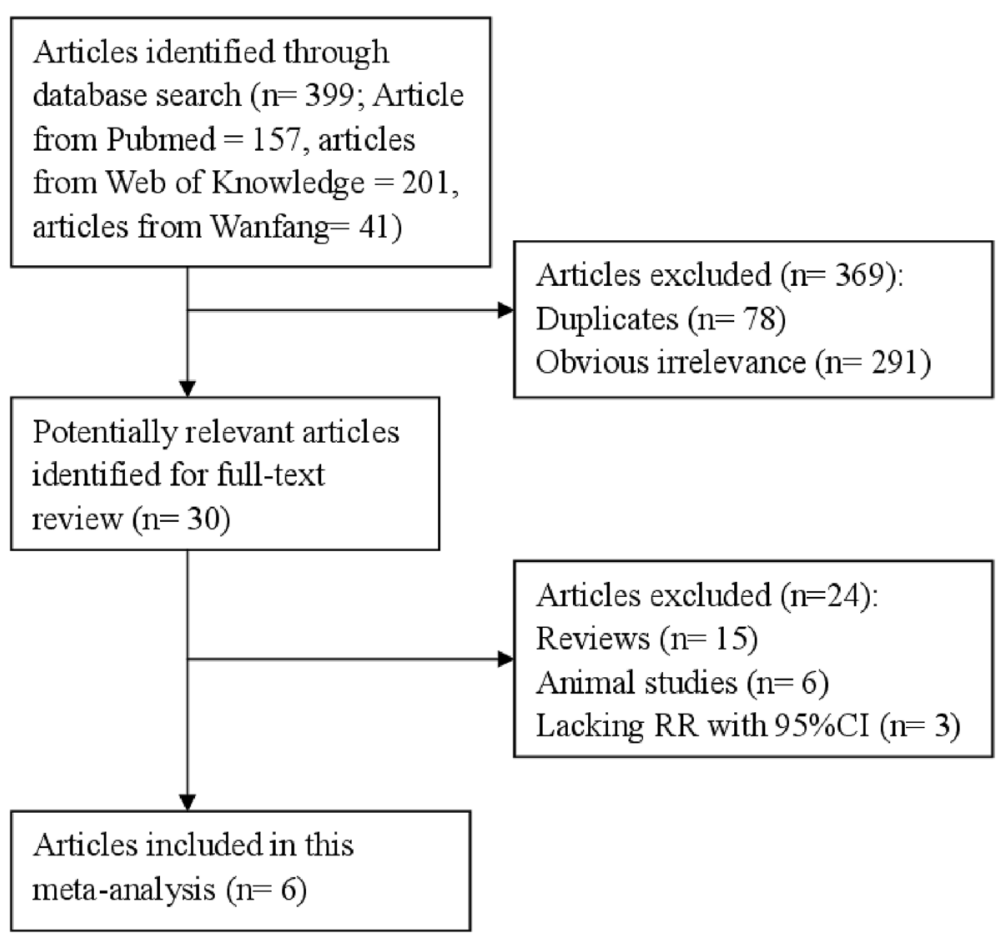

Fig. 1 Study selection process for this meta-analysis 


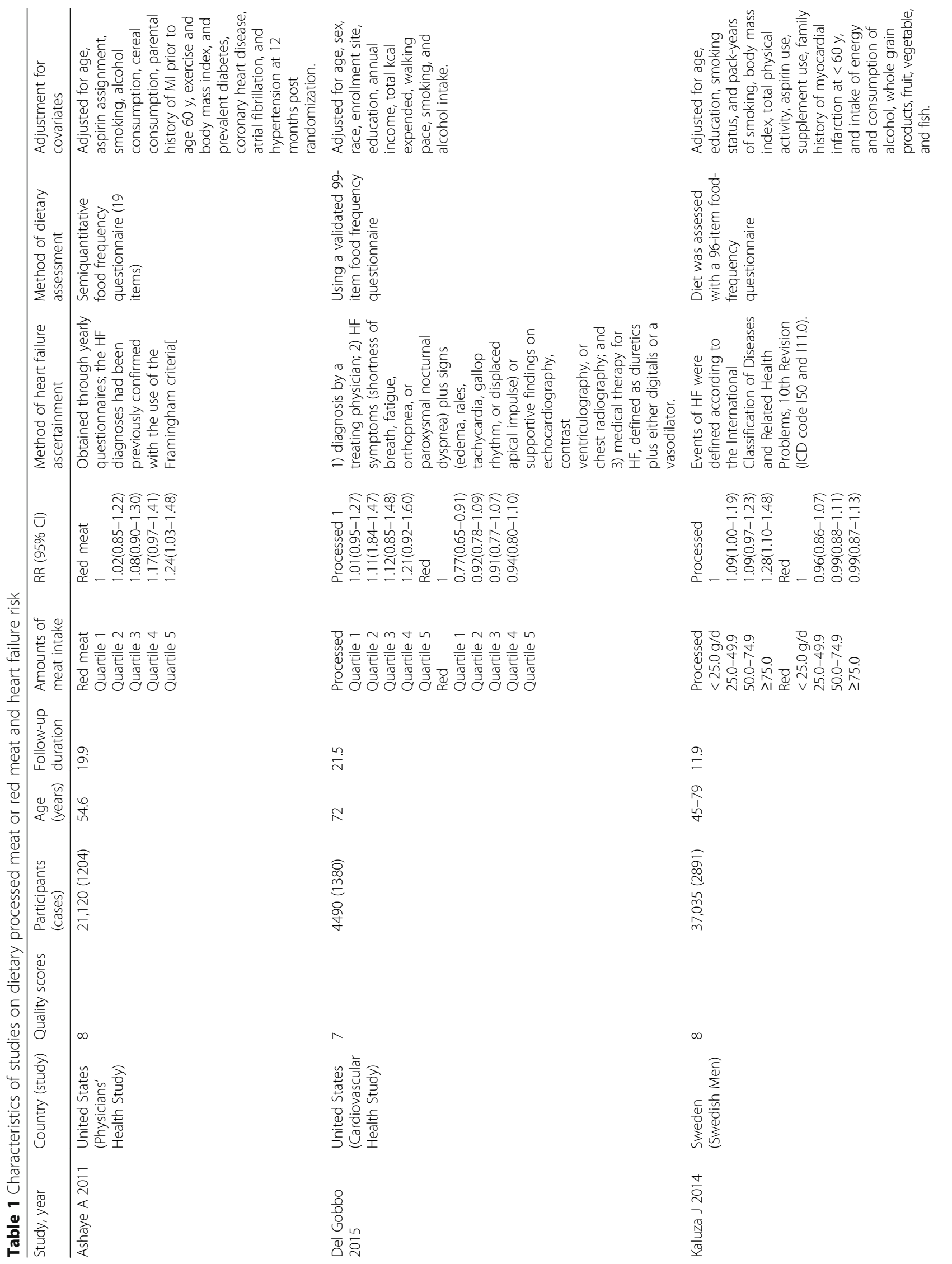




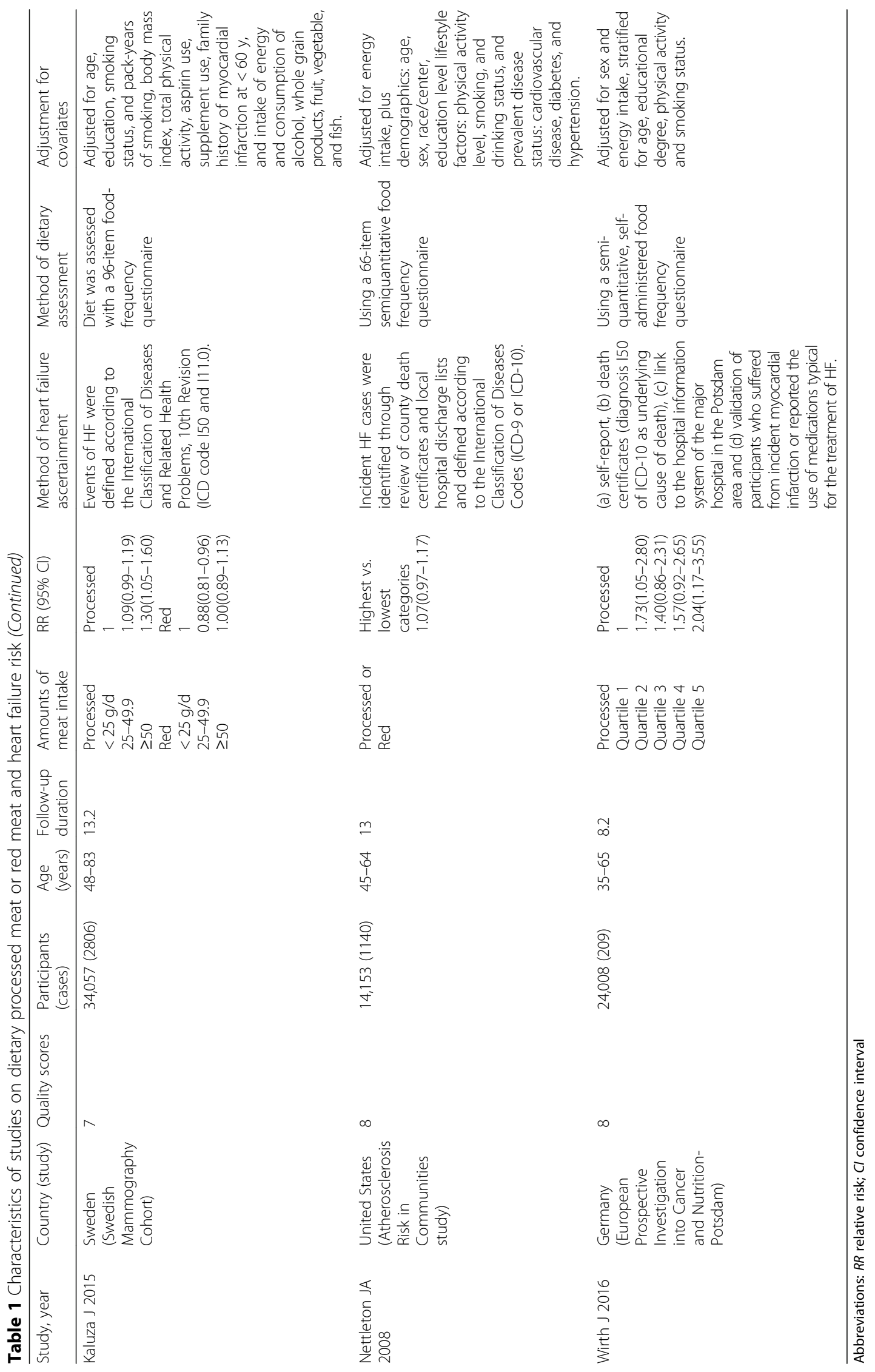


the risk of heart failure. Three studies were performed in North America and the other three studies were carried out in Europe. All of the suitable studies included 9630 heart failure cases and 134,863 participants. All of the six studies had relatively high quality (over 6 stars), with an average NOS score of 7.67. The characteristics of the included studies are summarized in Table 1.

\section{Processed meat intake and risk of heart failure}

Five studies were applied to assess the association between the processed meat intake and the risk of heart failure. It was reported that two studies presented an increased but non-significant association between the highest processed meat intake and risk of heart failure, while 3 studies demonstrated a positive relationship between processed meat intake and the risk of heart failure. The pooled RR for the highest category of processed meat intake versus lowest intake was 1.23 (95\% CI = $1.07-1.41 ; I^{2}=58.9 \%, P=0.045$; Fig. 2). In the stratified analysis by geographic location, a significant association was only found among the Europeans $[R R=1.33,95 \%$ $\mathrm{CI}=1.15-1.54]$, but not the Americans $[\mathrm{RR}=1.08,95 \%$ $\mathrm{CI}=0.99-1.18]$.

In this research, we found high between-study heterogeneity $\left(I^{2}=58.9 \%, P=0.045\right)$ regarding the association between processed meat intake and risk of heart failure. Munafo et al. [27] reported that between-study heterogeneity in meta-analyses is common. Therefore, it is essential to determine if heterogeneity exists between studies. Meta-regression was used for exploring the reasons. We found a significant impact on between-study heterogeneity for covariates of geographic location $(P=0.021)$. The between-study heterogeneity was reduced to zero for the Americans and $21.4 \%$ for the Europeans.

The Egger regression asymmetry test $(P=0.102)$ and filled funnel plot (Additional file 1: Figure S1) indicated that publication bias scarcely existed in the meta-analysis. Sensitivity analyses showed that no single study had essential effect on the overall result (Additional file 2: Figure S2).

\section{Red meat and heart failure risk}

Five publications were included to assess the association between red meat intake and the risk of heart failure. Merely one study reported a positive association between red meat intake and risk of heart failure $(\mathrm{RR}=$ $1.24,95 \% \mathrm{CI}=1.03-1.48$ ), while the remaining 4 studies suggested no significant association between these two. Pooled results pointed out that no statistically significant association exists in the overall studies ( $R R=1.04,95 \%$ $\mathrm{CI}=0.96-1.12, \mathrm{I}^{2}=38.2 \%, P_{\text {heterogeneity }}=0.167$; Fig. 3 ). The association was not significant in the Americans or the Europeans.

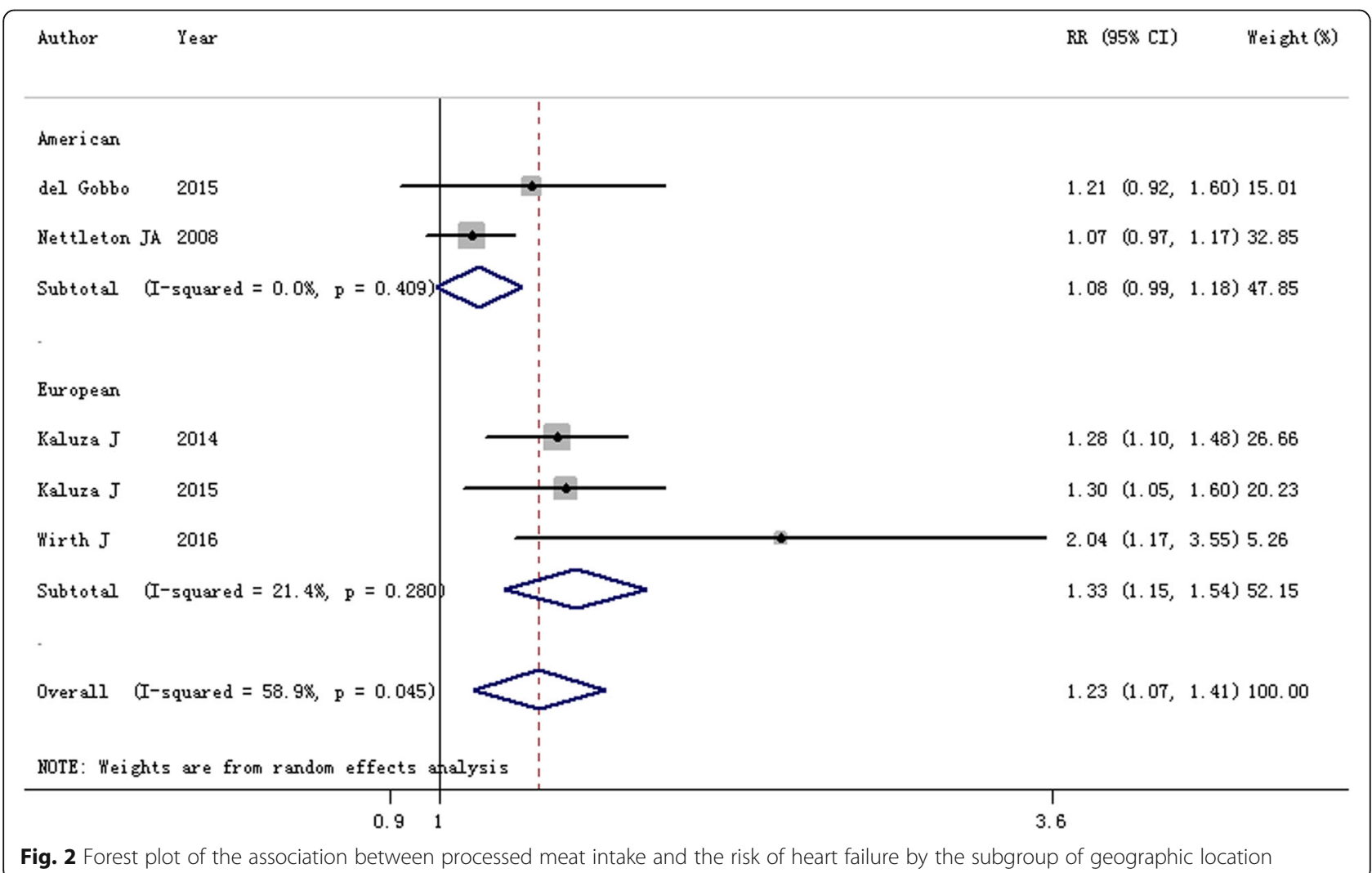




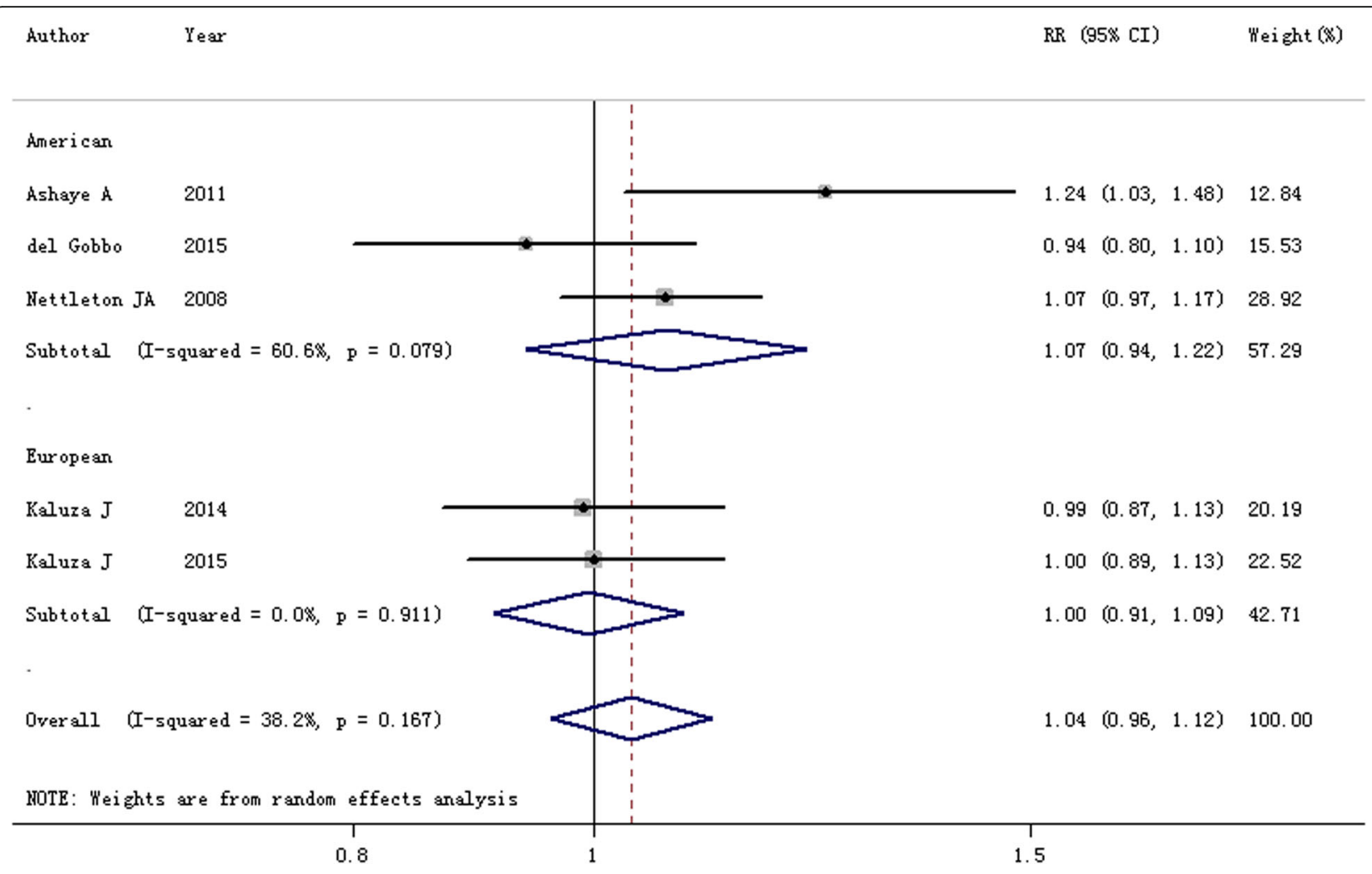

Fig. 3 Forest plot of the association between red meat intake and the risk of heart failure by the subgroup of geographic location

Rare publication bias was detected by using the Egger regression asymmetry test $(P=0.221)$ and filled funnel plot (Additional file 3: Figure S3). No single study affected the aggregate of results when one study at a time was removed (Additional file 4: Figure S4).

\section{Discussion}

This study conducted the most comprehensive analysis of the association between the intake of dietary processed meat and red meat and the risk of heart failure up to date. The overall analyses indicated that the highest category of processed meat intake was associated with increased risk of heart failure. An essential association was found among the Europeans, but not the Americans regarding the processed meat intake. However, the association was not marked between dietary red meat intake and risk of heart failure. Sensitivity analysis demonstrated that no single study is potential to affect the aggregate results when one study was removed at a time.

Recent studies suggested that the highest category of processed meat and red meat raised up the risk of coronary heart disease [28], stroke [29], cardiovascular disease [30], as well as all-cause mortality [31]. However, the present study only found out the highest category of processed meat intake is an increased risk factor for heart failure, but not red meat intake. The potential effect of processed meat on heart failure may be attributed to the higher amounts of sodium and food additives added into the meat during processing procedure. A previous study confirmed that higher dietary sodium intake [14] boosted the risk of heart failure since blood pressure is affected by high sodium intake. Furthermore, processed meat has been used as a marker of N-nitroso compound exposure and reported as a risk factor for heart failure.

In meta-analysis, this study discovered that processed meat intake increase the risk of heart failure among the Europeans, but not the Americans, which might be caused by the fact that the Europeans were inclined to the processed meat with more sodium [14], red meat, and other high-fat, high-calorie, high-cholesterol snacks.

Overall, several strengths characterized this metaanalysis. Firstly, the meta-analysis included the large number of cases and participants than a single study, which may yield more comprehensive results. Secondly, all of the included studies proposed prospective experimental design, which may not cause retrospective or selected bias. Thirdly, the association between risk of heart failure risk and processed meat and red meat intake was verified for the first time.

Some potential limitations in this study should be mentioned. First of all, the included studies in our 
analysis were merely from Europe and America. Therefore, more original studies that are conducted in other countries are warranted to further evaluate the relationship between meat intake and risk of heart failure. Second, evidence of high heterogeneity was detected in the relationship between processed meat intake and risk of heart failure. Although we extracted the RR with adjustment for most confounding factors from original studies, the between-study heterogeneity was not avoided since some of other exposures associated with consumption of processed meat may be a risk factor for heart failure. However, this high heterogeneity was resolved by meta-regression.

\section{Conclusion}

The findings from this meta-analysis indicated that processed meat intake, other than red meat intake, correlated with an increased risk of heart failure.

\section{Additional files}

Additional file 1: Figure S1. Filled funnel plot between processed meat intake and the risk of heart failure. (TIF $25 \mathrm{~kb}$ )

Additional file 2: Figure S2. Sensitivity analysis between processed meat intake and the risk of heart failure. (TIF $35 \mathrm{~kb}$ )

Additional file 3: Figure S3. Filled funnel plot between red meat intake and the risk of heart failure. (TIF $25 \mathrm{~kb}$ )

Additional file 4: Figure S4. Sensitivity analysis between red meat intake and the risk of heart failure. (TIF $36 \mathrm{~kb}$ )

\section{Abbreviations}

Cl: Confidence interval; NOS: Newcastle-Ottawa-Scale; RR: Relative Risk

\section{Acknowledgements}

We thank Prof. Scott Cunningham for his assistance with word editing.

\section{Funding}

General Project Foundation Supported by Science and Technology Committee of Yuzhong District of Chongqing (NO.20170130).

\section{Availability of data and materials}

The datasets generated during and/or analyzed during the current study are available in the manuscript.

\section{Authors' contributions}

$K C$ drafted the manuscript. KC, YBL and $L Z$ participated in the design of the study. KC, YBL and LJZ carried out the literature quality evaluation. XM and

PJ conceived of the study. All authors approved the final manuscript.

\section{Ethics approval and consent to participate}

Not Applicable.

\section{Consent for publication}

Not Applicable.

\section{Competing interests}

The authors declare that they have no competing interests.

\section{Publisher's Note}

Springer Nature remains neutral with regard to jurisdictional claims in published maps and institutional affiliations.

\section{Author details}

'Department of Cardiology, Chongqing General Hospital, No.1, Youyi Road, Yuzhong district, Chongqing 400016, People's Republic of China.

${ }^{2}$ Department of Cardiology, Second Affiliated Hospital of Zhejiang University, Hangzhou, People's Republic of China.

Received: 11 March 2018 Accepted: 13 March 2019

Published online: 29 March 2019

\section{References}

1. Steggall A, Mordi IR, Lang CC. Targeting Metabolic Modulation and Mitochondrial Dysfunction in the Treatment of Heart Failure. Diseases. 2017;5(2).

2. Fragasso G, Salerno A, Spoladore R, Bassanelli G, Arioli F, Margonato A. Metabolic therapy of heart failure. Curr Pharm Des. 2008;14(25):2582-91.

3. Beadle RM, Williams LK, Abozguia K, Patel K, Leon FL, Yousef $Z$, Wagenmakers A, Frenneaux MP. Metabolic manipulation in chronic heart failure: study protocol for a randomised controlled trial. Trials. 2011;12:140.

4. Verweij N, Eppinga RN, Hagemeijer Y, van der Harst P. Identification of 15 novel risk loci for coronary artery disease and genetic risk of recurrent events, atrial fibrillation and heart failure. Sci Rep. 2017:7(1):2761.

5. Li MP, Hu XL, Yang YL, Zhang YJ, Zhou JP, Peng LM, Tang J, Chen XP. Basigin rs8259 Polymorphism Confers Decreased Risk of Chronic Heart Failure in a Chinese Population. Int J Environ Res Public Health. 2017;14(2).

6. Djousse L, Akinkuolie AO, Wu JH, Ding EL, Gaziano JM. Fish consumption, omega-3 fatty acids and risk of heart failure: a meta-analysis. Clin Nutr. 2012; 31(6):846-53.

7. Li YH, Zhou CH, Pei HJ, Zhou XL, Li LH, Wu YJ, Hui RT. Fish consumption and incidence of heart failure: a meta-analysis of prospective cohort studies. Chin Med J. 2013;126(5):942-8.

8. Hou LN, Li F, Zhou Y, Nie SH, Su L, Chen PA, Tan WL, Xu DL. Fish intake and risk of heart failure: a meta-analysis of five prospective cohort studies. Experimental and therapeutic medicine. 2012;4(3):481-6.

9. Jiang WL, Gu HB, Zhang YF, Xia QQ, Qi J, Chen JC. Vitamin D supplementation in the treatment of chronic heart failure: a meta-analysis of randomized controlled trials. Clin Cardiol. 2016;39(1):56-61.

10. Ye Y, Li J, Yuan Z. Effect of antioxidant vitamin supplementation on cardiovascular outcomes: a meta-analysis of randomized controlled trials. PLoS One. 2013;8(2):e56803.

11. Khan H, Kunutsor SK, Kauhanen J, Kurl S, Gorodeski EZ, Adler Al, Butler J, Laukkanen JA. Fasting plasma glucose and incident heart failure risk: a population-based cohort study and new meta-analysis. J Card Fail. 2014; 20(8):584-92.

12. Gong F, Yao S, Wan J, Gan X. Chocolate Consumption and Risk of Heart Failure: A Meta-Analysis of Prospective Studies. Nutrients. 2017:9(4).

13. Kwok CS, Loke YK, Welch AA, Luben RN, Lentjes MA, Boekholdt SM, Pfister R, Mamas MA, Wareham NJ, Khaw KT, et al. Habitual chocolate consumption and the risk of incident heart failure among healthy men and women. Nutr Metab Cardiovasc Dis. 2016:26(8):722-34.

14. Graudal NA, Hubeck-Graudal T, Jurgens G. Reduced Dietary Sodium Intake Increases Heart Rate. A Meta-Analysis of 63 Randomized Controlled Trials Including 72 Study Populations. Front Physiol. 2016;7:111.

15. Liberati A, Altman DG, Tetzlaff J, Mulrow C, Gotzsche PC, loannidis JP, Clarke M, Devereaux PJ, Kleijnen J, Moher D. The PRISMA statement for reporting systematic reviews and meta-analyses of studies that evaluate health care interventions: explanation and elaboration. Ann Intern Med. 2009;151(4): W65-94.

16. Stang A. Critical evaluation of the Newcastle-Ottawa scale for the assessment of the quality of nonrandomized studies in meta-analyses. Eur J Epidemiol. 2010:25(9):603-5.

17. DerSimonian R, Laird N. Meta-analysis in clinical trials. Control Clin Trials. 1986;7(3):177-88

18. Higgins JP, Thompson SG, Deeks JJ, Altman DG. Measuring inconsistency in meta-analyses. Bmj. 2003:327(7414):557-60.

19. Higgins JP, Thompson SG. Controlling the risk of spurious findings from meta-regression. Stat Med. 2004;23(11):1663-82.

20. Egger M, Davey Smith G, Schneider M, Minder C. Bias in meta-analysis detected by a simple, graphical test. Bmj. 1997;315(7109):629-34.

21. Ashaye A, Gaziano J, Djousse L. Red meat consumption and risk of heart failure in male physicians. Nutr Metab Cardiovasc Dis. 2011;21(12):941-6.

22. Del Gobbo LC, Kalantarian S, Imamura F, Lemaitre R, Siscovick DS, Psaty BM, Mozaffarian D. Contribution of major lifestyle risk factors for incident heart 
failure in older adults: the cardiovascular health study. JACC Heart failure. 2015;3(7):520-8

23. Kaluza J, Akesson A, Wolk A. Processed and unprocessed red meat consumption and risk of heart failure: prospective study of men. Circulation Heart failure. 2014; 7(4):552-7.

24. Kaluza J, Akesson A, Wolk A. Long-term processed and unprocessed red meat consumption and risk of heart failure: a prospective cohort study of women. Int J Cardiol. 2015;193:42-6.

25. Nettleton JA, Steffen LM, Loehr LR, Rosamond WD, Folsom AR. Incident heart failure is associated with lower whole-grain intake and greater highfat dairy and egg intake in the atherosclerosis risk in communities (ARIC) study. J Am Diet Assoc. 2008;108(11):1881-7.

26. Wirth J, di Giuseppe R, Boeing H, Weikert C. A Mediterranean-style diet, its components and the risk of heart failure: a prospective population-based study in a non-Mediterranean country. Eur J Clin Nutr. 2016;70(9):1015-21.

27. Munafo MR, Flint J. Meta-analysis of genetic association studies. Trends in genetics : TIG. 2004:20(9):439-44.

28. Micha R, Wallace SK, Mozaffarian D. Red and processed meat consumption and risk of incident coronary heart disease, stroke, and diabetes mellitus: a systematic review and meta-analysis. Circulation. 2010;121(21):2271-83.

29. Chen GC, Lv DB, Pang Z, Liu QF. Red and processed meat consumption and risk of stroke: a meta-analysis of prospective cohort studies. Eur J Clin Nutr. 2013;67(1):91-5.

30. Pan A, Sun Q, Bernstein AM, Schulze MB, Manson JE, Stampfer MJ, Willett WC, Hu FB. Red meat consumption and mortality: results from 2 prospective cohort studies. Arch Intern Med. 2012:172(7):555-63.

31. Larsson SC, Orsini N. Red meat and processed meat consumption and all-cause mortality: a meta-analysis. Am J Epidemiol. 2014;179(3):282-9.

Ready to submit your research? Choose BMC and benefit from:

- fast, convenient online submission

- thorough peer review by experienced researchers in your field

- rapid publication on acceptance

- support for research data, including large and complex data types

- gold Open Access which fosters wider collaboration and increased citations

- maximum visibility for your research: over $100 \mathrm{M}$ website views per year

At $\mathrm{BMC}$, research is always in progress.

Learn more biomedcentral.com/submissions 